\title{
Myths and Realities of Writing for the Web
} COMMUNICATION CORNER No. 28

\author{
by Philip Yaffe
}

\begin{abstract}
Editor's Introduction
Each "Communication Corner" essay is self-contained; however, they build on each other. For best results, before reading this essay and doing the exercise, go to the first essay "How an Ugly Duckling Became a Swan," then read each succeeding essay.

It is often said that the advent of the World Wide Web has changed everything, including how people read texts and therefore how writers should write texts. Don't believe it. Good texts written for the web are essentially the same as good texts written for print.
\end{abstract}




\title{
Myths and Realities of Writing for the Web COMMUNICATION CORNER No. 28
}

\author{
by Philip Yaffe
}

Ever since it became popular, I have been hearing that writing for the web is different from writing for print. I have always been skeptical of this assertion and now after years of experience I am certain that it is wrong.

To paraphrase poet Gertrude Stein: "A text is a text is a text." Whether it is on a piece of paper or a computer screen is of little consequence. What makes a good text good is universal. It does not change because it is on paper or on a screen.

Let me demonstrate this by analyzing the plethora of articles that try to suggest otherwise.

The standard argument is web readers are in a hurry, so they probably aren't going to read the entire article as they would in a print publication.

My background is journalism. I have been a writer with The Wall Street Journal and editor of a local daily newspaper. During my first course in journalism 40 years ago, the professor said something rather shocking: "Newspaper readers are in a hurry, so they probably aren't going to read your entire article."

This was very demoralizing, because we all believed the objective of journalism was to write articles people would read all the way through. Our egos were bruised. The professor, who knew what we were thinking, continued. "Our purpose is not for people to read everything we write, but to dispense useful information. As a writer, you are not the best judge of what is useful. Only the reader is."

If you think about it, this assertion should come as no surprise. When you start reading an article in a newspaper, how often do you actually finish it? Chances are not very often. News articles are specifically designed to help you decide how much you really need to read, so you can quickly go on to something else. If this weren't the case, people wouldn't read newspapers at all, because it would take them all day to do so.

The fact is, all these articles about writing for the web generally tell you what journalists have known for centuries. There may be some technical things about writing for the web that should be taken into account, just as there are about writing for print. However, good writing is good writing, so the differences pale into insignificance compared to the similarities. 
To prove the point, here is a list of tips and recommendations proffered by these articles.

1. When you write for the web, you keep in mind that your readers probably aren't going to read your entire content as they would a print publication.

This statement is worth repeating because it is usually the "most important" thing these articles tell you. As we have just seen, it is nonsense. We could perhaps make a distinction between a daily newspaper and a weekly or monthly magazine. Magazine readers generally do have more time to read. Nevertheless, it still is not the objective of professional writers that people read their articles from beginning to end, because for the vast majority of readers doing so simply wouldn't be worth their while.

\section{Limit your text to $600-700$ words.}

Again, this statement is nonsense. There is no arbitrary limit to how many words people will read; that depends on the article and their interest in it.

Personally, I have stopped reading almost anything I find on the web that is less than 600-700 words, because such articles are generally shallow and prescriptive. So many of them offer a list of three, five, or 10 things you must do to achieve a particular objective. But they seldom give you sufficient (if any) explanation of why you should do them, other than because the writer says so.

Another argument asserts you should limit yourself to only 600-700 words "because people don't like to read long texts on the screen." This is also fallacious. If people find an article sufficiently interesting but difficult to read on the screen, they will simply print it out and read it on paper.

\section{Use headings and subheadings.}

The reason for this, we are told, is because web surfers like to read in "nuggets," i.e. small bits of text rather than long, flowing verbiage. This is a valid point. And this is what newspapers and magazines have been doing forever.

There is, however, a much more important reason for using headings and subheadings. They allow readers to pick and choose the information they want to read, which is also something newspapers and magazines have been doing forever.

Most good articles start off with an overview (the "lead" in journalese). The overall theme is then broken down into five or six sub-themes. As a reader, you may not be interested in exploring all of them, but only one or two in particular. The subheadings show you exactly 
where they are. In other words, you don't have to read everything in the article to find the particular information you are looking for. The subheadings lead you right to it.

\section{Write shorter paragraphs.}

Again, look at newspapers and magazines. Long paragraphs are generally conspicuous by their absence. Occasionally, you will even find paragraphs as short as a single sentence.

Why?

The technical reason is to help the reader's eye to move comfortably down the page. A more important reason is shorter paragraphs make it easier for readers to rapidly absorb what is written. Grammarians sometimes criticize newspapers and magazines for their illogical paragraphs. However, they make no pretence of being logical, but rather psychological.

It is true search engines will more easily pick up your text if you consistently use shorter paragraphs. This is indeed specific to writing for the web and not to be neglected. However, since you should be writing this way anyhow, search engine optimization (SEO) becomes a bonus, not a raison d'être.

\section{Write tightly.}

In other words, eliminate unnecessary adjectives, adverbs, jargon, etc., that add nothing to meaning; but simply clutter the page. Duh! This is what professional newspaper and magazine writers do as a matter of course; otherwise, they wouldn't have a job.

Writing tightly also means eliminating anything that is not germane to the text. That odd fact you picked up or that cute anecdote may be very interesting. However, if they do not advance the purpose of your article, they become distractions. Get rid of them and save them for another article where they might really add something.

\section{Put key information up front.}

"Because web users scan articles, you need to get out the basic tenants of your article in the beginning of the text."

Duh! Newspaper and magazine readers also scan articles. In fact, there is a journalistic technique called the "inverted pyramid" that specifically addresses this phenomenon. The inverted pyramid is like a triangle standing on its point. All the key information is put at the top (the "lead"), with detailed information filling in the rest of the pyramid (the "body) in descending order of importance. 
By reading the first couple of paragraphs or so, you get a good overview of what the article is all about. You can then decide to continue reading or go on to something else. Moreover, because the information in the body is arranged in descending order of importance, you can stop reading at virtually any point you want in full confidence that you will not be missing something seriously important further down.

Arranging information in descending order of importance makes the inverted pyramid extremely useful to readers and a major challenge to writers. Mastering the art of putting information into descending order of importance is a key attribute that distinguishes a professional writer (one who gets paid for writing) from an amateur.

In conclusion, note that this article runs to 1382 words. If you have read this far, it is because you felt you were getting something of value. It is as short as it possibly could be while still saying everything that needed to be said. If it had been artificially restricted to $600-700$ words, it would have been too short-and most likely a terrible waste of your time.

\begin{abstract}
About the Author
Philip Yaffe was born in Boston, Massachusetts, in 1942 and grew up in Los Angeles, where he graduated from the University of California with a degree in mathematics and physics. In his senior year, he was also editor-in-chief of the Daily Bruin, UCLA's daily student newspaper. He has more than 40 years of experience in journalism and international marketing communication. At various points in his career, he has been a teacher of journalism, a reporter/feature writer with The Wall Street Journal, an account executive with a major international press relations agency, European marketing communication director with two major international companies, and a founding partner of a specialized marketing communication agency in Brussels, Belgium, where he has lived since 1974. He is the author of more than 30 books, which can be found easily in Amazon Kindle.
\end{abstract}

DOI: $10.1145 / 3419837$ 